\title{
A solid-state switch containing an electrochemically switchable bistable poly[n]rotaxane $\dagger$
}

\author{
Wenyu Zhang, ${ }^{a}$ Erica DeIonno, ${ }^{* b}$ William R. Dichtel,${ }^{a c}$ Lei Fang, ${ }^{d}$ Ali Trabolsi, ${ }^{d}$ John-Carl Olsen, ${ }^{d}$ \\ Diego Benítez, ${ }^{a}$ James R. Heath ${ }^{* c}$ and J. Fraser Stoddart ${ }^{* d}$
}

\author{
Received 14th July 2010, Accepted 3rd October 2010 \\ DOI: 10.1039/c0jm02269a
}

\begin{abstract}
Electrochemically switchable bistable main-chain poly[n]rotaxanes have been synthesised using a threading-followed-by-stoppering approach and were incorporated into solid-state, molecular switch tunnel junction devices. In contrast to single-station poly[n]rotaxanes of similar structure, the bistable polymers do not fold into compact conformations held together by donor-acceptor interactions between alternating stacked $\pi$-electron rich and $\pi$-electron deficient aromatic systems. Films of the poly $[n]$ rotaxane were incorporated into the devices by spin-coating, and their thickness was easily controlled. The switching functionality was characterised both (1) in solution by cyclic voltammetry and (2) in devices containing either two metal electrodes or one metal and one silicon electrode. Devices with one silicon electrode displayed hysteretic responses with applied voltage, allowing the devices to be switched between two conductance states, whereas devices containing two metal electrodes did not exhibit switching behaviour. The electrochemically switchable bistable poly $[n]$ rotaxanes offer significant advantages in synthetic efficiency and ease of device fabrication as compared to bistable small-molecule [2]rotaxanes.
\end{abstract}

\section{Introduction}

The field of molecular electronics ${ }^{1}$ has continued to grow over the past several years, despite significant challenges to the realisation of reliable molecular electronic circuits. One particular focus in this area has been on molecular switches ${ }^{2}$ where the electronic states of the molecules can be controlled externally. The use of molecular switches is both promising and challenging. They are attractive components in devices on account of both their scalability and the potential to tune their functionality at a molecular level. In this way, the exact desired switch may be realised. A major difficulty, however, lies in coupling the molecules and electrodes in a molecular device. It turns out that this step greatly complicates matters, because the molecular device functionality is dependent on the system, not just the molecule. ${ }^{1}$ Over time, researchers have seen both extrinsic ${ }^{3}$ switching mechanisms, in which the molecules are passive components, and more interestingly, intrinsic mechanisms, in which the switching is based on a molecular property, such as a conformational change. Examples of intrinsic switching mechanisms include redox switching, ${ }^{4}$ configurational isomerisation, ${ }^{5}$ and tautomerisation ${ }^{6}$ of certain molecules, as well as the ones based on the translational isomerisation of mechanically interlocked molecules (MIMs). The

\footnotetext{
${ }^{a}$ Department of Chemistry and Biochemistry, University of California, Los Angeles, 405 Hilgard Ave., Los Angeles, CA, 90095, USA

${ }^{b}$ The Aerospace Corporation, 2350 E. El Segundo Blvd., El Segundo, CA, 90245, USA

'Division of Chemistry and Chemical Engineering, California Institute of Technology, 1200 East California Boulevard, Pasadena, CA, 91125, USA ${ }^{d}$ Department of Chemistry, Northwestern University, 2145 Sheridan Road, Evanston, IL, 60208, USA

$\dagger$ This paper is part of a Journal of Materials Chemistry themed issue in celebration of the 70th birthday of Professor Fred Wudl.
}

controllable relative motions of the components of MIMs, ${ }^{7}$ such as bi- or multistable ${ }^{8}$ [2]catenanes and [2]rotaxanes, give rise to changes in conductivity within molecular electronic devices (MEDs), and thus have been used as the active component in a variety of circuits, including isolated junctions ${ }^{9}$ and memories, ${ }^{10}$ and switching between high and low conductance states of the devices has been correlated to the translational isomerisation of the molecules.

The electromechanical switching of both bistable donoracceptor [2] rotaxanes and [2]catenanes has been investigated in a variety of environments, ${ }^{\mathbf{8}, \mathbf{1 1}}$ including solution, flat surfaces, ${ }^{\mathbf{1 1}}$ polymer matrices, pendant side chains on polymers, ${ }^{12}$ metal nanoparticle surfaces, ${ }^{13}$ mesoporous silicon nanoparticle surfaces, ${ }^{14}$ and tunnel junctions. ${ }^{15}$ The switching based on relative molecular motions of surface-immobilised MIMs has recently been visualised ${ }^{16}$ by scanning tunneling microscopy. Two bottlenecks, however, have limited the further development of MEDs based on MIMs - the multistep syntheses used to prepare amphiphilic derivatives and the non-scalable process of forming densely packed Langmuir-Blodgett (LB) films of the molecules during device fabrication. When organic monolayers are used in MEDs, defect-free LB films prevent the device from shorting and protect the molecular switching elements from degradation $^{9 d}$ during the deposition of the top electrode. Herein, we investigate the ability of electrochemically switchable bistable poly $[n]$ rotaxanes to address both of these challenges - they are available through a short, efficient synthetic pathway and can be readily incorporated into MEDs as films prepared by spincoating.

In the past two decades, although mechanically bonded macromolecules ${ }^{17}$ such as main-chain ${ }^{18}$ and pendant ${ }^{19}$ poly$[n]$ catenanes have proven to possess extraordinary mechanical and dynamic properties, the synthetic availability of these 
systems has limited their materials applications. Specifically, incorporating a large number of cyclobis(paraquat- $p$-phenylene) $\left(\mathrm{CBPQT}^{4+}\right)^{20}$ rings, a key component of the switchable MIMs, into polymeric systems was impractical, as it was limited by the moderate efficiency of the template-directed "clipping" process used for mechanical bond formation. Two complementary synthetic advances ${ }^{21}$ have recently overcome this problem: the development of kinetically controlled stoppering and macrocyclisation reactions that occur under mild conditions that do not disrupt host-guest binding ${ }^{22}$ and the formation ${ }^{23}$ of mechanical bonds under thermodynamic control through the reversible nucleophilic opening of the $\mathrm{CBPQT}^{4+}$ ring. Donoracceptor poly $[n]$ rotaxanes were synthesised by threading $\pi$ electron-deficient $\mathrm{CBPQT}^{4+}$ rings onto a polymer "thread" containing $\pi$-electron-rich 1,5-dioxynaphthalene (DNP) moieties in the backbone followed by attaching bulky stoppers to the end groups. These poly $[n]$ rotaxanes exhibited a folded structure stabilised by secondary interactions between non-encircled DNP and the outside of the $\mathrm{CBPQT}^{4+}$ ring. Based on our successful attempts in the highly efficient syntheses of foldable poly$[n]$ rotaxanes $^{24}$ and side-chain poly[2]catenanes ${ }^{12}$ using dynamiccontrolled reactions, we prepared a main-chain bistable poly$[n]$ rotaxane $1 \cdot 4 \mathrm{nPF}_{6}$ (Fig. 1), where the switchable components are incorporated directly into the polymer chain and thus achieved a material with a high density of functionality. The switching properties of the poly[ $n]$ rotaxane were characterised in solution before it was employed as the active component in a solid-state switch.

Polymeric materials for solid-state switches have a distinct advantage over small molecules in terms of device fabrication. Thin polymer films can be deposited using a spin-coater, spraycoater or ink-jet printing techniques. ${ }^{25}$ The thickness of the films can be easily tuned. Polymeric materials can also be printed on flexible substrates using low cost printing techniques, ${ }^{26}$ in order to incorporate these materials into MEDs. Many MEDs are based on small molecules and use either self-assembled monolayers (SAMs) or LB films. In the case of bistable [2]rotaxane molecules, the SAMs are not dense enough to be used in a solidstate device, because the creation of the top contact typically results in a shorted device. Therefore, to form an ordered, dense molecular film, a LB trough must be used. The films are of very high quality and the packing can be precisely controlled, but the process is low-throughput and requires the use of amphiphilic molecules. Thus far, solid-state devices incorporating [2]rotaxanes and [2]catenanes have been highly ordered, with the functional groups well aligned with respect to the electrodes. The polymer systems fabricated by spin-coating, spray-coating, or printing techniques will result in thin films in which the molecular alignment is somewhat random. In this work, we demonstrate that (i) main-chain bistable poly $[n]$ rotaxanes with high density of functionality can be synthesised with relative ease, (ii) the switching process of the poly $[n]$ rotaxane can be realised both in solution and in the solid state, and (iii) ordered films are not required to access the functionality of the polymer switch, given the appropriate choice of electrode materials.

Fig. 1 shows the molecular structure of poly[n]rotaxane $1.4 \mathrm{nPF}_{6}$ and its switching mechanism. The linear polymer precursor 3 contains two $\pi$-electron donating aromatic moieties, a tetrathiafulvalene (TTF) unit (green) and a DNP unit (red). MIMs with these moieties have been shown to exhibit hysteretic behaviour, or switching, in a number of different environments, including in solution and in the solid state. In such bistable rotaxanes, there is always an equilibrium between the tetracationic $\mathrm{CBPQT}^{4+}$ ring $^{27}$ (blue) encircling the TTF unit (ground

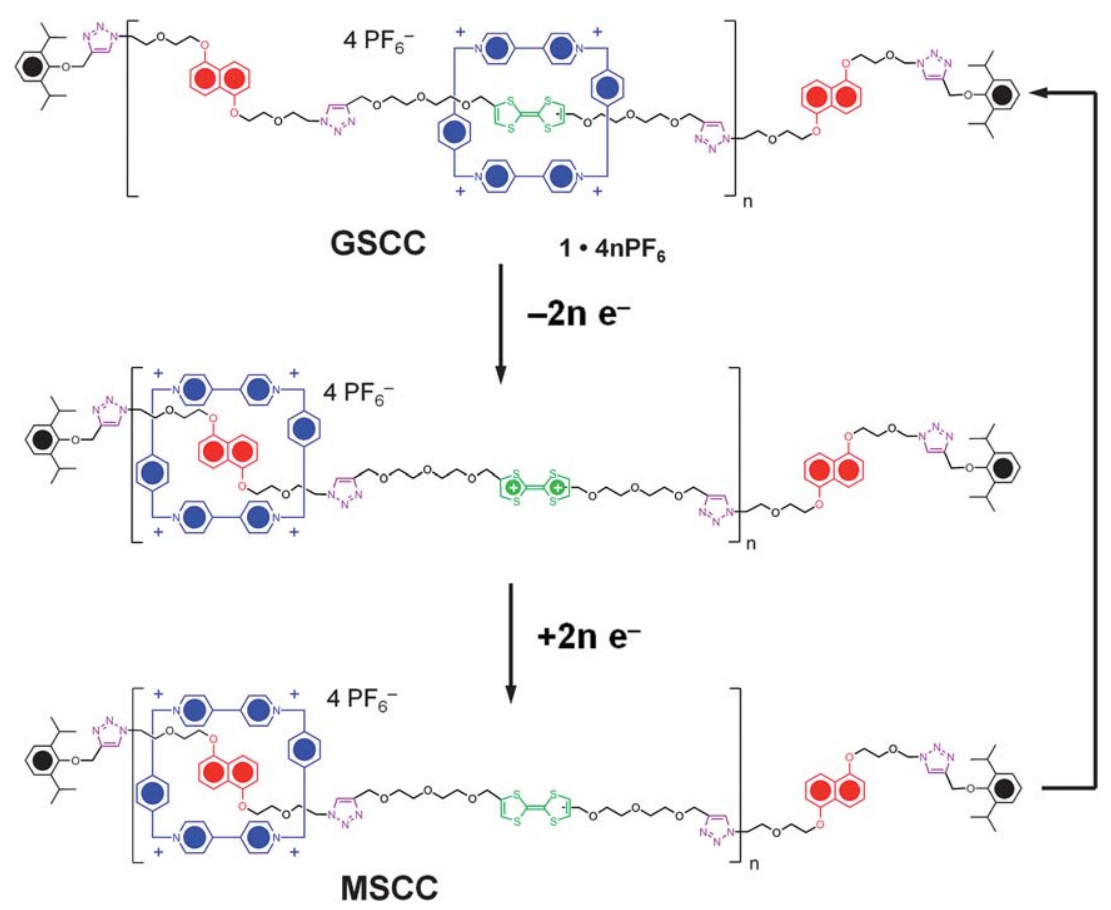

Fig. 1 The ground-state co-conformer (GSCC), oxidised form, and the metastable-state co-conformer (MSCC) of the bistable poly[n]rotaxane $1 \cdot 4 \mathrm{nPF}_{6}$. 
state co-conformer, GSCC) and the DNP unit (metastable state co-conformer, MSCC). The first oxidation of the TTF moiety forms a radical cation $\left(\mathrm{TTF} \rightarrow \mathrm{TTF}^{\bullet+}\right.$ ) and creates a strong repulsion of the $\mathrm{CBPQT}^{4+}$ ring, driving it to the DNP site. Reduction of the cationic species back to neutral forms the MSCC, which re-equilibrates to the equilibrium mixture of GSCC and MSCC. The difference between GSCC and MSCC can be monitored using cyclic voltammetry $(\mathrm{CV})$ because the first oxidation voltage of the TTF units in the MSCC is distinctly lower ${ }^{11 b}$ than that in the GSCC because of the absence of the encircling $\mathrm{CBPQT}^{4+}$ on TTF moieties in the MSCC.

\section{Results and discussion}

\section{Synthesis of the polymer precursors}

The TTF-containing monomer precursor $2{ }^{28}$ the DNPcontaining monomer $4,{ }^{24}$ the stopper precursor $6,{ }^{24}$ and the cyclophane CBPQT $4 \mathrm{PF}_{6}{ }^{29}$ were synthesised (Scheme 1) according to literature procedures. Monomer 3 was synthesised by reacting the TTF-containing precursor $\mathbf{2}$ and propargyl bromide in THF with a yield of $85 \%$.

\section{Synthesis of the polymer dumbbell}

The polymerisation was carried out (Scheme 1) by using copper(I)-catalysed azide-alkyne cycloaddition ${ }^{30}$ (CuAAC) in dimethyl formamide (DMF). The TTF-dialkyne 3 and a diazide- bearing DNP derivative 4 underwent step-growth polymerisation $^{31}$ to form the linear polymer dumbbell $\mathbf{5}$ with alternating TTF-DNP units. This structural feature is essential as it guarantees that each cyclophane acts as a switching component and therefore the polymer has the highest possible density of functional groups. The ratio of the two monomers was varied (Table 1) to control the polymer molecular weight distribution. The crude products were then precipitated into an aqueous EDTA solution to remove the catalysts, followed by redissolving in $\mathrm{CH}_{2} \mathrm{Cl}_{2}$ and precipitating into $\mathrm{Me}_{2} \mathrm{CO}$ to remove unreacted monomers and oligomeric side-products.

\section{Synthesis of the poly[n]rotaxane}

The polymer dumbbell 5 and 1.5 equivalents of $\mathbf{C B P Q T} \cdot 4 \mathrm{PF}_{6}$ were dissolved in DMF, forming a dark-green solution, indicating (Scheme 1) the threading of the cyclophane onto the polymer dumbbell. The mixture was stirred for $24 \mathrm{~h}$ to ensure the complete threading before it was treated with the alkyne-bearing stopper precursor 6 under CuAAC conditions. The resulting poly $[n]$ rotaxane $1 \cdot 4 \mathrm{nPF}_{6}$ was filtered through DNP-functionalised PS-coDVB cross-linked $\operatorname{resin}^{24}$ to remove the free CBPQT $\cdot 4 \mathrm{PF}_{6}$. It was then dissolved in $\mathrm{DMF}$, precipitated in THF to remove the unreacted stopper precursor $\mathbf{6}$, followed by redissolving and precipitating in EDTA solution to remove the catalysts. The stoppered polymer dumbbell 7 was synthesised in a similar way.

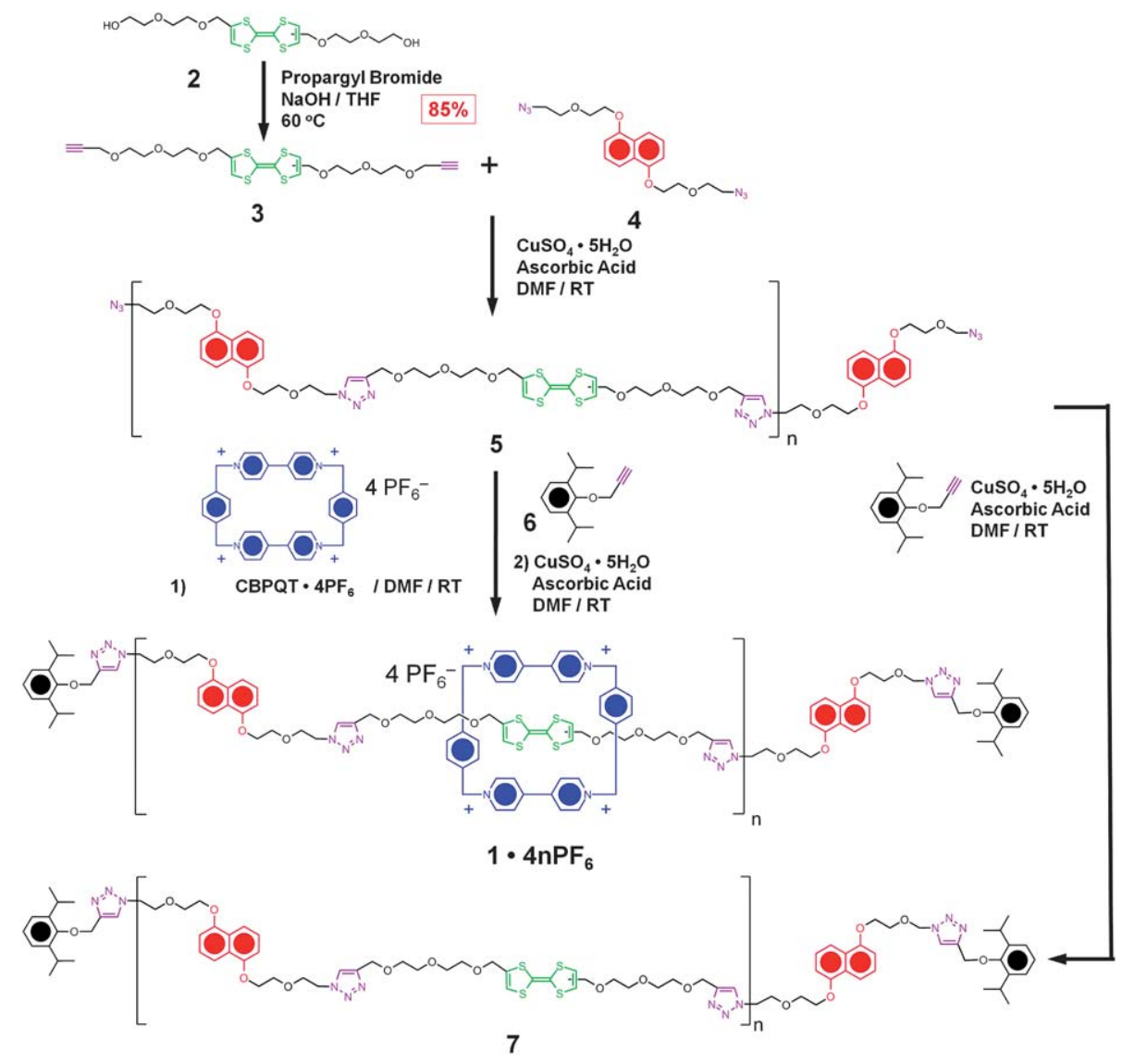

Scheme 1 Synthesis of the poly $[n]$ rotaxane $1 \cdot 4 \mathrm{nPF}_{6}$ and the polymer dumbbell 7. 


\section{Polymer molecular weight analyses}

Gel permeation chromatography (GPC), coupled with lightscattering, was employed to analyse the size and molecular weight distributions of the polymer dumbbell 5. Table 1 shows that the molecular weight distributions $\left(M_{w}=8-94 \mathrm{kDa}\right)$ were well-controlled by varying the ratio of the two starting monomers, and that the polydispersity indices (PDI $=1.40-1.47)$ were in the normal range for step-growth polymer.

Table 1 Gel permeation chromatography (GPC) of polymer dumbbell $\mathbf{5}(\mathbf{a}-\mathbf{c})$. The number-average molecular weights $\left(M_{n}\right)$ of $\mathbf{5 ( a - c )}$ were determined by multi-angle light scattering.

\begin{tabular}{lllll}
\hline $\begin{array}{l}\text { Polymer } \\
\text { sample }\end{array}$ & $\begin{array}{l}N_{T T F}: \\
N_{D N P}\end{array}$ & $\begin{array}{l}\text { Retention volume } \\
(\mathrm{mL})\end{array}$ & $\begin{array}{l}\text { Polydispersity } \\
\text { index }\end{array}$ & $\begin{array}{l}M_{n} \\
(\mathrm{kDa})\end{array}$ \\
\hline $\mathbf{5 a}$ & 0.800 & 29.5 & 1.40 & 8 \\
$\mathbf{5 b}$ & 0.900 & 28.9 & 1.47 & 25 \\
$\mathbf{5 c}$ & 1.000 & 28.0 & 1.45 & 94 \\
\hline
\end{tabular}

Noticeably, the GPC trace of poly $[n]$ rotaxane $1 \cdot 4 \mathrm{nPF}_{6}$ showed decreased retention volume compared to the corresponding polymer dumbbell 5 (Fig. 2), a phenomenon contrary to the previously studied $^{24}$ foldable all-DNP poly[ $\left.n\right]$ rotaxanes, where the addition of the $\mathrm{CBPQT}^{4+}$ ring caused the polymer to fold and led to an increased retention volume. We speculate that this new situation arises because $\mathbf{1} \cdot 4 \mathrm{nPF}_{6}$ lacks the secondary noncovalent interactions which are essential for the formation of the

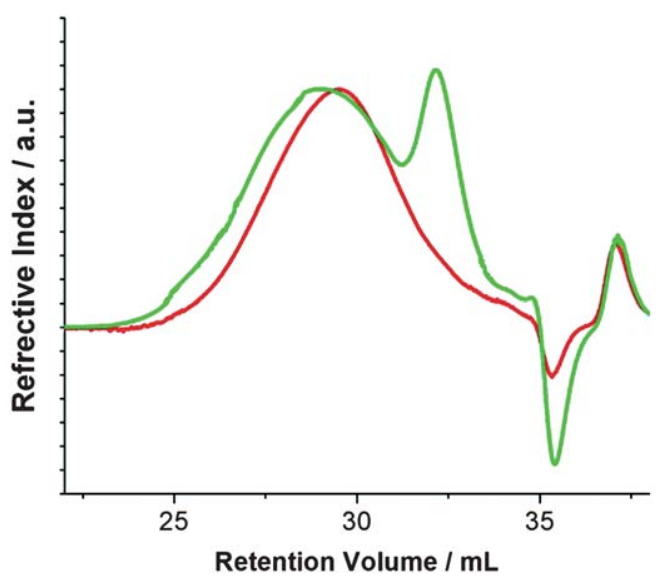

Fig. 2 GPC traces of the polymer dumbbell $5 \mathbf{a}$ (red) and the corresponding poly $[n]$ rotaxane $1 \mathbf{a} \cdot 4 \mathrm{nPF}_{6}$ (green). The retention volume of the latter (28.9) is smaller than the former (29.5), indicating the increase of particle size upon the formation of the poly $[n]$ rotaxane.

folded structure. Instead, the polymer remains in its random coil morphology upon threading of the $\mathrm{CBPQT}^{4+}$ rings, and the hydrodynamic volume of the polymer chains increases accordingly, causing a decrease of retention volume in GPC. Such characteristics are optimal for solid-state switch applications because drastic changes in morphology could compromise the mechanical strength and integrity of the material. Further evidence for the absence of folding in the bistable

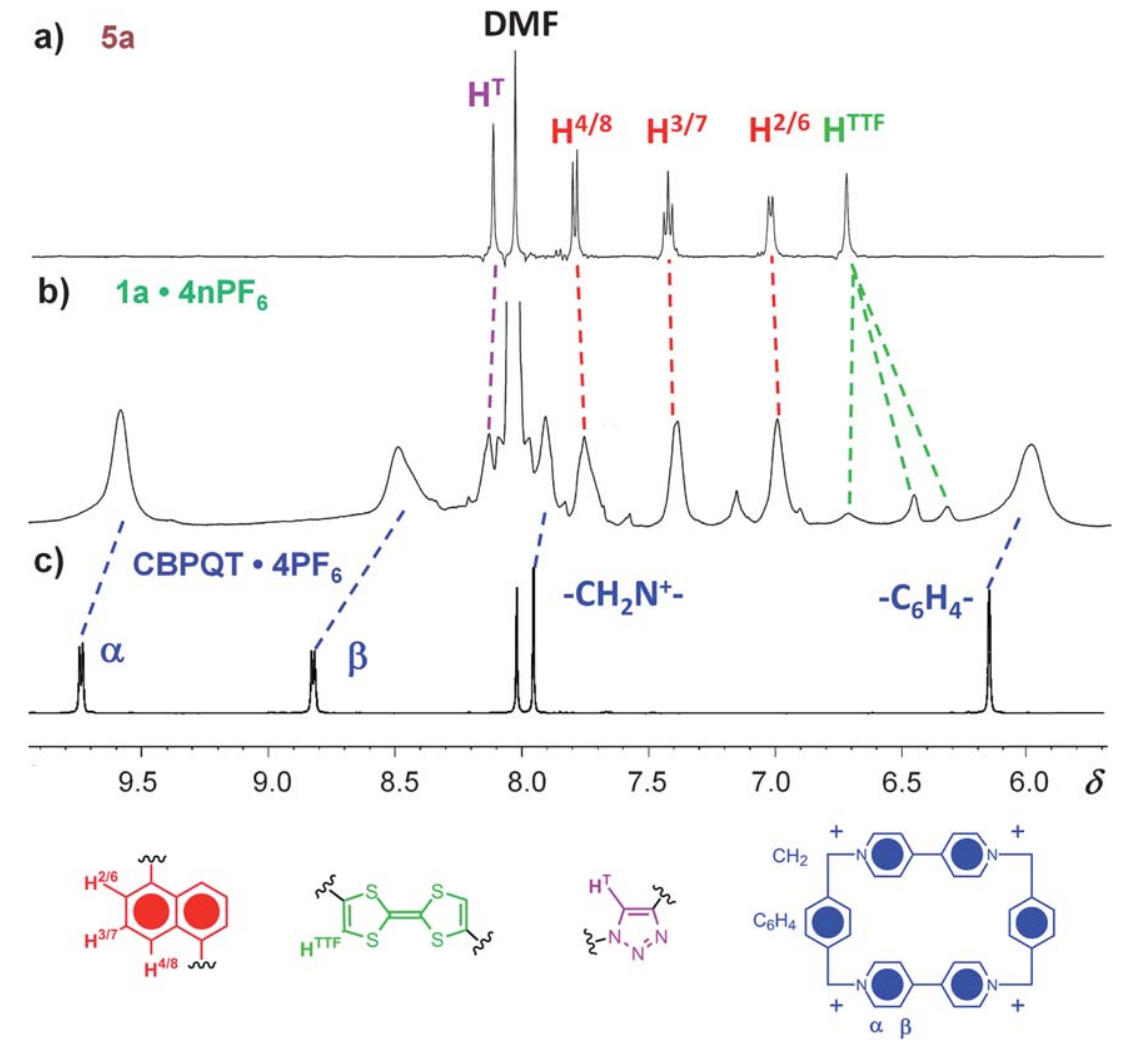

Fig. $3{ }^{1} \mathrm{HNMR}$ spectra of (a) the polymer dumbbell $\mathbf{5 a}$, (b) the poly[ $\left.n\right]$ rotaxane $\mathbf{1 a} \cdot 4 \mathrm{nPF}_{6}$, and (c) the cyclophane $\mathbf{C B P Q T} \cdot 4 \mathrm{PF} 6$, in DMF- $d_{7}$, at $298 \mathrm{~K}$. Upon the formation of the poly[n]rotaxane, chemical shifts of $\mathrm{CBPQT}^{4+}$ protons show noticeable upfield changes, while the TTF aromatic proton separates into several signals from various co-conformers. 

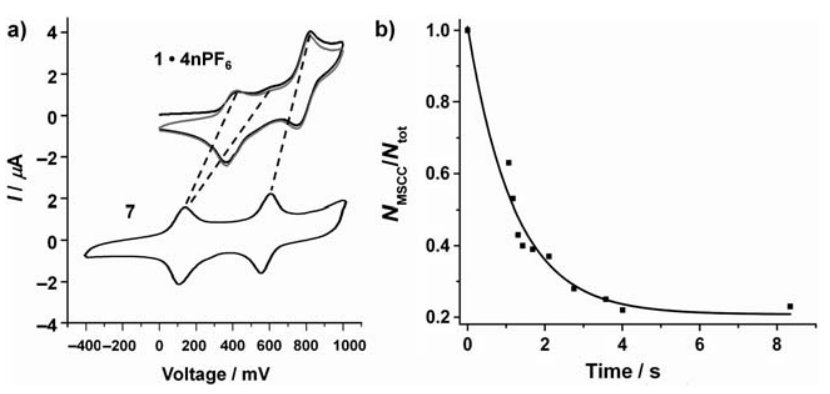

Fig. 4 (a) Up: The first (black trace) and second (grey trace) CVs (298 K/ scan rate $\left.=200 \mathrm{mV} \mathrm{s}^{-1} / v \mathrm{~s} \mathrm{Ag} / \mathrm{AgCl}\right)$ of the bistable poly[ $\left.n\right]$ rotaxane $\mathbf{1} \cdot 4 \mathrm{nPF}_{6}$ in $\mathrm{MeCN}(298 \mathrm{~K},[\mathrm{TTF}]=1 \mathrm{mM}, 0.1 \mathrm{M}$ tetrabutylammonium hexakisfluorophosphate as electrolyte). (b) Fitted first order exponential decay profiles of the relaxation of the MSCC to the GSCC and time constants $(\tau)$ obtained from the $\mathrm{CV}$ data, measured for the solution at room temperature at different scan rates $\left(100-800 \mathrm{mV} \mathrm{s}^{-1}\right)$.

poly $[n]$ rotaxanes was obtained from NMR spectroscopic studies. The shoulder peak in the trace of $\mathbf{1 a} \cdot 4 \mathrm{PF}_{6}$ indicates the existence of a certain amount of unbound CBPQT.4PF 6 . Since CBPQT $4 \mathrm{PF}_{6}$ is a small molecule exerting marginal light scattering response, the presence of such a peak should not affect the molecular weight measurement of the macromolecular species during GPC.

The molecular weight of $1 \cdot 4 \mathrm{nPF}_{6}$ could not be measured by the static light-scattering technique directly because the chargetransfer absorption band between the TTF units and the $\mathrm{CBPQT}^{4+}$ rings overlaps with the laser wavelength $(690 \mathrm{~nm})$ used for the molecular weight-measuring method. Instead, the $M_{n}$ of $\mathbf{1} \cdot 4 \mathrm{nPF}_{6}$ was measured by using nuclear magnetic resonance (NMR) end-group analysis.

\section{NMR spectroscopic analyses}

The ${ }^{1} \mathrm{H}$ NMR spectrum (Fig. 3) of $\mathbf{1} \cdot 4 \mathrm{nPF}_{6}$ provides clear evidence for the formation of the interlocked structure. The downfield shift of the $\mathrm{CBPQT}^{4+}$ proton signals are a typical phenomena for its binding with electron-rich moieties. ${ }^{32}$ The protons on the DNP units retain their "unbound" values, suggesting that there is no secondary binding between them and the $\mathrm{CBPQT}^{4+}$ ring and therefore no folded substructures are formed during the ring-threading process. Calculations using the integration of the signals from the polymer dumbbell (DNP and $\mathrm{TTF}$ ) and those from the $\mathrm{CBPQT}^{4+}$ ring indicated that $90 \%, 84 \%$, and $72 \%$ of the TTF moieties were encircled by the $\mathrm{CBPQT}^{4+}$ cyclophane in $\mathbf{1 a} \cdot 4 \mathrm{nPF}_{6}, \mathbf{1 b} \cdot 4 \mathrm{nPF}_{6}$, and $\mathbf{1 c} \cdot 4 \mathrm{nPF}_{6} \cdot \mathrm{We}$ believe that such a decrease in coverage is caused by the higher energy barrier $^{33}$ it is necessary to overcome in moving the threaded $\mathrm{CBPQT}^{4+}$ rings along longer polymer threads $\left(M_{5 a}<M_{5 b}<\right.$ $\left.M_{5 c}\right)$.

\section{Cyclic voltammetry studies}

The electrochemically induced switching phenomenon of the poly $[n]$ rotaxane was firstly studied in solution.Fig. 4a shows two successive $\mathrm{CV}$ cycles of the poly[n]rotaxane $1 \cdot 4 \mathrm{nPF}_{6}$ solution in $\mathrm{MeCN}$ compared to that of the control polymer dumbbell 7 in $\mathrm{CH}_{2} \mathrm{Cl}_{2}$ under identical conditions. The two oxidation features recorded at $+433 \mathrm{mV}$ and $+621 \mathrm{mV}$ correspond to the $\mathrm{TTF} \rightarrow$ $\mathrm{TTF}^{\bullet+}$ oxidation of the MSCC and GSCC, respectively. The TTF unit inside the $\mathrm{CBPQT}^{4+}$ ring has a significantly higher oxidation voltage. The stronger peak at $+820 \mathrm{mV}$ is assigned to the second oxidation $\left(\mathrm{TTF}^{\bullet+} \rightarrow \mathrm{TTF}^{2+}\right.$ ), which is independent of the co-conformer as the $\mathrm{CBPQT}^{4+}$ ring encircles DNP upon first oxidation. In the second scan, the height of the $+621 \mathrm{mV}$ peak is reduced - with a concurrent increase in the height of the peak at $+433 \mathrm{mV}$ - on account of the fact that some of the MSCCs have not relaxed to the ground state during the scan. Following electromechanical actuation, recovery of the MSCC/GSCC equilibrium is an activated process. A control experiment (Fig. 4a, bottom) using the polymeric dumbbell 7 showed two oxidation peaks at $+118 \mathrm{mV}$ and $+594 \mathrm{mV}$ which do not change between the first and second scans.

The kinetics of relaxation of the MSCC back to the GSCC in $\mathbf{1} \cdot 4 \mathrm{nPF}_{6}$ can be quantified by variable scan rate $\mathrm{CV}$ and fitting (Fig. 4b) a first-order exponential decay model to the population ratios of the metastable state and the relaxation times. The role of the physical environment on molecular electromechanical switching in solutions, ${ }^{34}$ on surfaces, ${ }^{11 b, 35}$ in polymer gels ${ }^{15,8 f}$ and self-assembled monolayers, ${ }^{8 e, 9 a}$ as well as in molecular switch tunnel junctions (MSTJs), ${ }^{36}$ has already been probed in considerable detail. For $\mathbf{1} \cdot 4 \mathrm{nPF}_{6}$, the free energy of activation $\left(\Delta G^{\ddagger}\right)$ was found to be $17.1( \pm 0.9) \mathrm{kcal} \mathrm{mol}^{-1}$ in $\mathrm{MeCN}$. This value is $\sim 2 \mathrm{kcal} \mathrm{mol}^{-1}$ higher than that observed for previously studied bistable [2]rotaxanes in solution, and thus, once again, indicates that the switching behaviour of a bistable [2]rotaxane is strongly influenced by the nature of the environment. This observation, however, is contrary to its switching behaviour ${ }^{12}$ of a TTF$\mathrm{CBPQT}^{4+}$-based pendant poly[2]catenane, the kinetics of which are not affected by the colloidal nature of the nanostructure. In this case, the polymeric material itself acts as a matrix that is similar to previously investigated solid-state junctions, such as polymer gels and SAMs, where an increased barrier to switching back to the GSCC was also observed.

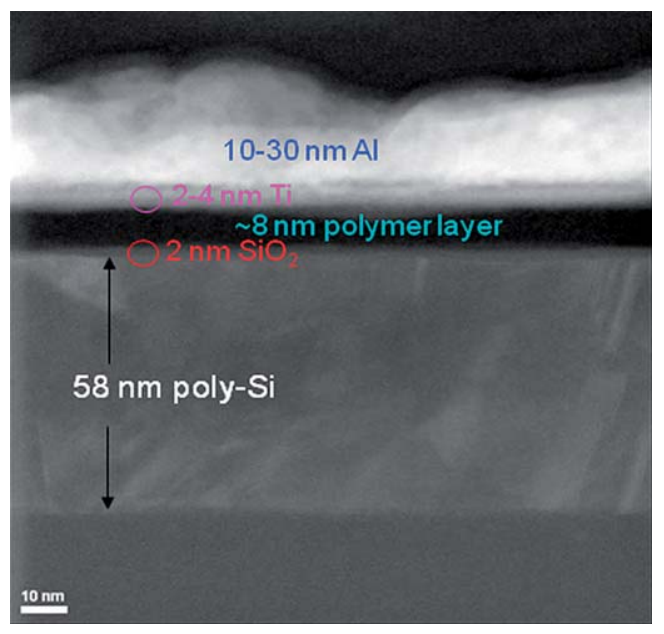

Fig. 5 High resolution scanning transmission electron microscopy of a Si/polymer/metal device cross-section, illustrating the sandwich structure of a polymer switch device. 
a)

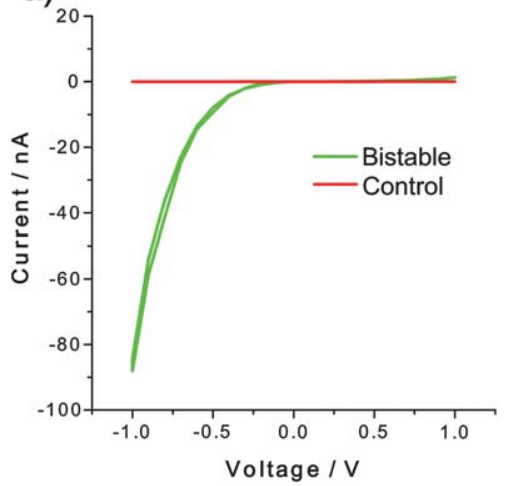

b)

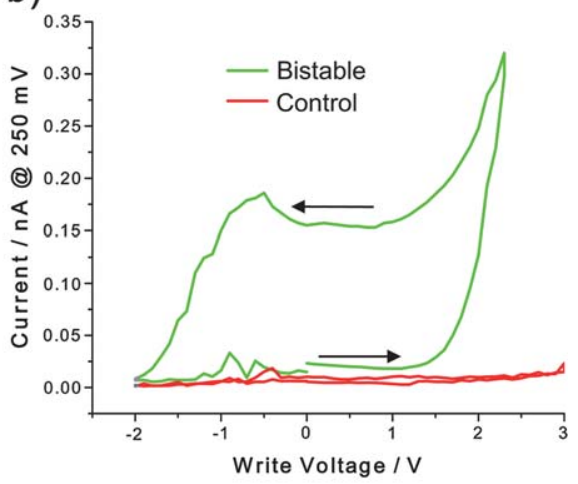

Fig. 6 (a) $I-V$ and (b) remnant characteristics of Si/polymer/Ti/Al devices. The green traces correspond to the switching polymer devices, and the control devices are shown in red. The bistable poly[n]rotaxane $1 \cdot 4 \mathrm{nPF}_{6}$ (green) shows hysteresis in the remnant scan and an on:off ratio of $\sim 7$. The polymer dumbbell 7 (red) does not switch. The arrows on the remnant plot (right) indicate the direction of the scan.

\section{Solid-state switch}

Solid-state switches were fabricated using both the bistable poly $[n]$ rotaxane $1 \cdot 4 \mathrm{PF}_{6}$ and the polymer dumbbell 7 , with no switching functionality, as a control. Bottom electrodes were either metallic (M) or doped poly-Si ( $\mathrm{Si})$. The top electrodes in all cases were metal (M). The polymer films were spin-coated on the electrodes and tuned to approximately $10 \mathrm{~nm}$. Devices were evaluated using both a typical current-voltage $(I-V)$ scan and a remnant scan. ${ }^{37}$ The remnant measurement reveals the threshold voltages for turning the device on and off and the magnitude of the onloff ratio as well as eliminating the capacitance response. One of the silicon devices, which was crosssectioned using a focused ion beam and imaged using high resolution scanning transmission electron microscopy (HRSTEM), is shown in Fig. 5. The cross section reveals a smooth and continuous $8 \mathrm{~nm}$ thick polymer layer.

In the case of the devices with the poly-Si bottom electrodes, the bistable poly $[n]$ rotaxane $1 \cdot 4 \mathrm{nPF}_{6}(\mathrm{BP})$ and the dumbeell polymer 7 (DP) behaved very differently. The $I-V$ and remnant ${ }^{38}$ characteristics from Si/Polymer/M devices are shown in Fig. 6. Most significantly, the bistable poly $[n]$ rotaxane $1 \cdot 4 \mathrm{nPF}_{6}$ device showed stable hysteresis in the remnant measurement (green trace in Fig. 6b). The current started out low (off state) and as the read bias was swept to $+1.5 \mathrm{~V}$, the device began to increase in current up to $+2.3 \mathrm{~V}$. This higher current state (on state) persisted until $-0.8 \mathrm{~V}$, when the device returned to the low current state (off). The on:off ratio of this particular device was $\sim 7$. The polymer dumbbell 7 has no hysteresis in the remnant measurement (red trace in Fig. 6b) and the magnitude of the current is greatly reduced compared to that observed for the bistable poly $[n]$ rotaxane devices.

The bistable poly $[n]$ rotaxane devices could be cycled between the on and off states up to 20 times. The current level, however, along with the magnitude of the on:off ratio, decreased with repeated cycling, which most likely indicates degradation of the polymer films with applied voltage. We believe that the solution to improving device robustness may be found in metal organic frameworks (MOFs) which incorporate MIMs. ${ }^{39}$ In contrast to polymer films, where the polymer backbone is stressed and degraded when subjected to repeated dynamics-i.e., switching-MOFs incorporating MIMs will yield rigid structures that are intrinsically robust. a)

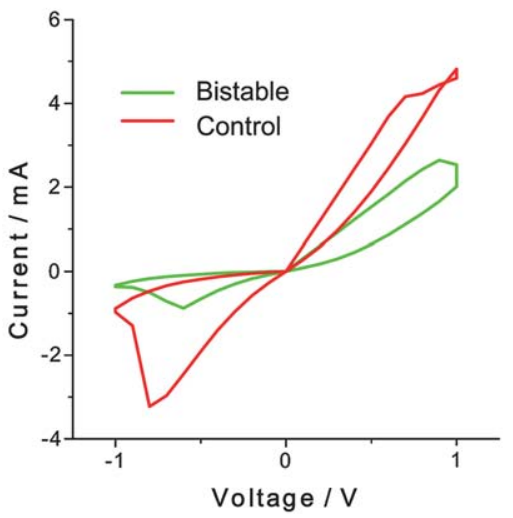

b)

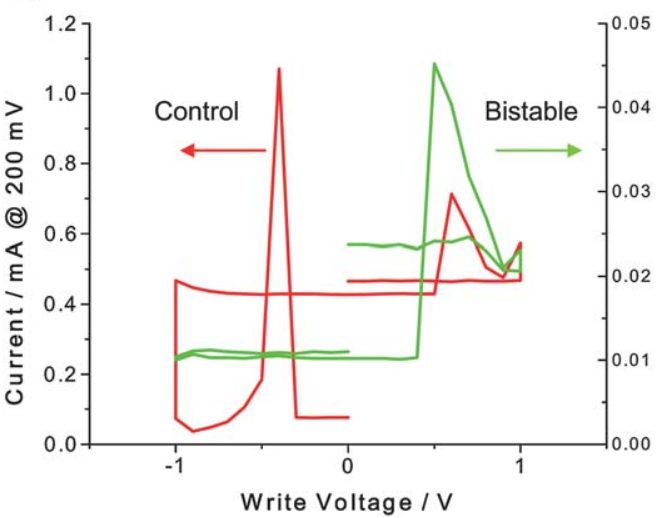

Fig. 7 (a) $I-V$ and (b) remnant characteristics of Au/polymer/Ti/Au devices. The green traces correspond to the bistable poly[n]rotaxane $1 \cdot 4 \mathrm{nPF} 6$ devices, while the polymer dumbbell 7 devices are shown in red. Similar hysteresis is observed in the $I-V$ plots for both the bistable poly $[n]$ rotaxane and the polymer dumbbell devices. The remnant measurement shows no stable hysteresis for either type of device. 
A second set of devices was fabricated using metallic bottom electrodes. The behaviour of these devices was very different from the poly-Si devices. Both the bistable poly[n]rotaxane $1 \cdot 4 \mathrm{nPF}_{6}$ devices and the dumbbell polymer 7 devices showed (Fig. 7a) similar $I-V$ characteristics and current levels. In the $\mathrm{Si} /$ Polymer/M devices, the current magnitude was very different depending on which polymer was present in the device. For a device where the behaviour is dominated by the molecular properties and not the interfacial ones, a change in the molecular structure should yield a change in the $I-V$ characteristics. The remnant characteristics from the $\mathrm{M} / \mathrm{BP} / \mathrm{M}$ and $\mathrm{M} / \mathrm{DP} / \mathrm{M}$ devices are shown in Fig. 7b. Although there was some hysteresis present in the $I-V$ scan, the remnant characteristics of these devices did not show consistent hysteresis and the devices - both with the bistable poly $[n]$ rotaxane $1 \cdot 4 \mathrm{PF}_{6}$ and the dumbbell polymer 7did not exhibit stable switching behaviour. This molecule-independent type of behaviour has been noted previously in devices with metal electrodes ${ }^{40}$ and other studies have shown that the molecule/electrode interactions in some cases can dominate the transport characteristics of devices. ${ }^{41}$

\section{Conclusions}

Using highly efficient synthetic methods, we have prepared a main-chain bistable poly $[n]$ rotaxane $1 \cdot 4 \mathrm{nPF}_{6}$ with wellcontrolled molecular structure and a high density of functional groups along the polymer chain. GPC studies have shown that the molecular weight of the polymer can be readily controlled by varying the stoichiometry of the starting monomers, and that the polymer retains its random coil nature even after the mechanically interlocked structures have been formed. Cyclic voltammetry and ${ }^{1} \mathrm{H}$ NMR spectroscopic studies have provided evidence for switching in solution, a process which is similar to previously investigated small-molecule analogues. Variable scanning rate $\mathrm{CV}$ was also used to measure the barrier of relaxation from the MSCC to the GSCC. The $\Delta G^{\ddagger}$ value of the switching of $\mathbf{1} \cdot \mathrm{nPF}_{6}$ was determined to be $17.1( \pm 0.9) \mathrm{kcal} \mathrm{mol}^{-1}$ in $\mathrm{MeCN}$, a value similar to that of previously studied materials, based on polymer gels or SAMs. The bistable poly[n]rotaxane $1 \cdot 4 \mathrm{nPF}_{6}$ was incorporated into two different types of devices using spin coating, which resulted in disordered thin films of polymer. The polymer dumbbell 7 was used as a control. In devices based on a metal/polymer/metal architecture, the polymer dumbbell 7 and the bistable poly[n]rotaxane $1 \cdot 4 \mathrm{nPF}_{6}$ showed very similar $I-V$ characteristics and no stable remnant signature. However, when the bottom electrode material was changed to polysilicon, the two polymers exhibits sharply differing behaviours. The bistable poly $[n]$ rotaxane $1 \cdot 4 \mathrm{nPF}_{6}$ showed hysteresis and bistability in the solid-state-i.e., the ability to switch between the on and off states - whereas the control polymer dumbbell 7 showed no hysteresis. This investigation reinforces the importance of choosing the appropriate electrode materials when fabricating MEDs, as well as showing that disordered films exhibit the same switching functionality as related devices incorporating well-ordered and aligned LB films of bistable [2]rotaxanes or bistable [2]catenanes. The polymerbased form allows access to a variety of high-throughput processing techniques, including spin-coating, spray-coating and ink-jet printing.

\section{Experimental section}

\section{Methods and materials}

Chemicals were purchased from commercial suppliers and were used as received. Size exclusion chromatography was performed on an Agilent 1100 Series liquid chromatography system with two ViscoGELTM columns. Multiangle light scattering was measured with Wyatt DAWN Heleos II spectrometer, while refractive index measurements were recorded with a Wyatt Optilab rEX spectrometer. Number-average molecular weights $\left(M_{\mathrm{n}}\right)$, weight-average molecular weights $\left(M_{\mathrm{w}}\right)$ and polydispersities ( $\mathrm{PDI}=M_{\mathrm{w}} / M_{\mathrm{n}}$ ) were determined relative to linear polystyrene $\left(\mathrm{GPC}_{\mathrm{PSt}}\right) .{ }^{1} \mathrm{H}$ and ${ }^{13} \mathrm{C}$ NMR spectra were recorded on a Bruker DRX500 (500 MHz) or AV600 (600 MHz) spectrometer, with the residual solvent resonance as the internal standard. Electrochemistry was performed using a Gamry Reference 600 potentiostat/galvanostat/ZRA. Fast atom bombardment mass spectra (FAB) were obtained on a JEOL JMS-600H high resolution mass spectrometer equipped with a FAB probe.

\section{Synthesis of the TTF monomer}

$\mathrm{NaOH}(1.09 \mathrm{~g}, 27.2 \mathrm{mmol})$ was added to a solution of $2(0.60 \mathrm{~g}$, $1.36 \mathrm{mmol})$ in THF $(15 \mathrm{~mL})$. A solution of propargyl bromide in $\mathrm{PhMe}(\mathrm{w} / \mathrm{w} 80 \%, 1.21 \mathrm{~mL}, 8.17 \mathrm{mmol})$ was then added to the suspension. The heterogeneous mixture was heated at $60^{\circ} \mathrm{C}$ for $3 \mathrm{~h}$ and was then filtered through Celite. The solvent was evaporated under reduced pressure. The resulting residue was dissolved in $\mathrm{CH}_{2} \mathrm{Cl}_{2}$ and washed with brine $(2 \times 50 \mathrm{~mL})$. Evaporation of the solvent afforded a brown solid. Chromatography $\left(\mathrm{SiO}_{2}, 1: 4 \mathrm{Et}_{2} \mathrm{O} / \mathrm{CH}_{2} \mathrm{Cl}_{2}\right)$ provided 3 as a red-brown solid $(0.59 \mathrm{~g}, 79 \%)$. ${ }^{1} \mathrm{H}$ NMR $\left(500 \mathrm{MHz}, \mathrm{CD}_{2} \mathrm{Cl}_{2}\right.$ ): $\delta=6.23$ (s, $2 \mathrm{H}, \mathrm{TTF}-\mathbf{H}), 4.27$ (s, $\left.4 \mathrm{H}, \mathrm{TTF}-\mathrm{CH}_{2}\right), 4.16\left(\mathrm{~d}, 4 \mathrm{H},{ }^{4} \mathrm{~J}=2 \mathrm{~Hz}\right.$, $\left.\mathrm{OCH}_{2} \mathrm{C} \equiv \mathrm{CH}\right), 3.53-3.67\left(\mathrm{~m}, 16 \mathrm{H}, \mathrm{CH}_{2} \mathrm{O}\right), 2.46\left(\mathrm{t}, 2 \mathrm{H},{ }^{4} \mathrm{~J}=2\right.$ $\left.\mathrm{Hz}, \mathrm{OCH}_{2} \mathrm{C} \equiv \mathrm{CH}\right) ;{ }^{13} \mathrm{C}$ NMR $\left(125 \mathrm{MHz}, \mathrm{CD}_{2} \mathrm{Cl}_{2}\right): \delta=134.5$, 134.4, 116.2, 116.1, 79.7, 74.0, 70.3, 70.2, 69.3, 69.0, 68.0, 58.1. MS (FAB): Calcd for $\mathrm{C}_{22} \mathrm{H}_{28} \mathrm{O}_{6} \mathrm{~S}_{4} m / z=516.077$. Found $m / z=$ 516.075 .

\section{General polymerisation procedure}

Monomers $3(150 \mathrm{mg}, 0.29 \mathrm{mmol})$ and $\mathbf{4}(\mathbf{5 a}, \mathbf{3 : 4}=0.80: 1.0 ; \mathbf{5 b}$, $\mathbf{3 : 4}=0.90: 1.0 ; \mathbf{5 c}, \mathbf{3 : 4}=1.0: 1.0)$, ascorbic acid $(10.2 \mathrm{mg}, 0.058$ $\mathrm{mmol})$ and $\mathrm{CuSO}_{4} \cdot 5 \mathrm{H}_{2} \mathrm{O}(7.2 \mathrm{mg}, 0.029 \mathrm{mmol})$ were dissolved in DMF $(2 \mathrm{~mL})$. The mixture was stirred under $\mathrm{Ar}$ for $24 \mathrm{~h}$. In the case of $\mathbf{5 c}$, another $1 \mathrm{mg}$ of $\mathbf{4}$ was added to the solution, along with ascorbic acid $(0.05 \mathrm{mg})$ and $\mathrm{CuSO}_{4} \cdot 5 \mathrm{H}_{2} \mathrm{O}(0.03 \mathrm{mg})$, after which the reaction mixture was stirred for a further $3 \mathrm{~h}$. The mixture was then added dropwise to an aqueous EDTA solution $(0.1 \mathrm{M}, 5 \mathrm{~mL})$, forming a yellow precipitate. The precipitate was collected by centrifugation before being washed with $\mathrm{H}_{2} \mathrm{O}(2 \times$ $5 \mathrm{~mL}$ ) and dried under high vacuum. The resulting solid was dissolved in $\mathrm{CH}_{2} \mathrm{Cl}_{2}(0.5 \mathrm{~mL})$ and precipitated into $\mathrm{Me}_{2} \mathrm{CO}$ $(5 \mathrm{~mL})$ to give the product. The solid was once again recovered by centrifugation and finally dried under high vacuum. ${ }^{1} \mathrm{H}$ NMR spectra of 5a-c are almost identical except for some marginal integral differences. A representative ${ }^{1} \mathrm{H}$ NMR data for $\mathbf{5 a}$ is provided here: ${ }^{1} \mathrm{H}$ NMR $\left(500 \mathrm{MHz}, \mathrm{CD}_{2} \mathrm{Cl}_{2}\right.$ ): $\delta=8.09$ (b, $2 \mathrm{H}$, 
Triazole-H), 7.76 (b, 4H, Ar- $\left.\mathbf{H}^{2 / 6}\right), 7.40$ (b, 4H, Ar- $\left.\mathbf{H}^{3 / 7}\right), 6.90$ (b, $\left.4 \mathrm{H}, \mathrm{Ar}-\mathbf{H}^{4 / 8}\right), 4.67-3.52\left(\mathrm{~m}, 32 \mathrm{H}, \mathrm{CH}_{2} \mathrm{O}\right), 3.48$ (b, 4H, $\mathrm{CH}_{2}$-Triazole).

\section{Synthesis of the poly[n|rotaxane}

A solution of CBPQT $4 \mathrm{PF}_{6}(48.1 \mathrm{mg}, 0.0437 \mathrm{mmol})$ and the polymer thread $5\left(29.1 \mathrm{mg}, N_{\mathrm{DNP}}=0.0728 \mathrm{mmol}\right)$ in $\mathrm{DMF}$ ( $2 \mathrm{~mL}$ ) was stirred at room temperature for $24 \mathrm{~h}$. A purple solution, indicative of threading, resulted. Stock solutions containing the stopper precursor $4(1.6 \mathrm{mg}, 7 \mu \mathrm{mol})$, ascorbic acid $(0.1 \mathrm{mg}, 0.7 \mu \mathrm{mol})$ and $\mathrm{CuSO}_{4} \cdot 5 \mathrm{H}_{2} \mathrm{O}(0.1 \mathrm{mg}, 0.4 \mu \mathrm{mol})$, were then added to the solution. The reaction mixture was stirred under Ar at room temperature overnight. Resin-supported DNP was added to the solution for 10 min before being removed by filtration. This step was repeated until the resin ceased turning red. The solution was then added to an aqueous EDTA solution $(0.1 \mathrm{M}, 5 \mathrm{~mL})$, forming a green precipitate. The precipitate was recovered by centrifugation, washed with $\mathrm{H}_{2} \mathrm{O}(2 \times 5 \mathrm{~mL})$ and dried under high vacuum for $2 \mathrm{~h}$. The solid was dissolved in a minimum amount of DMF and precipitated when added to THF $(5 \mathrm{~mL})$. The resulting poly $[n]$ rotaxane was once again recovered by centrifugation and dried under vacuum.

\section{Solid-state device fabrication}

Solid-state switches were fabricated by spinning a thin film $(\sim 10$ $\mathrm{nm}$ ) of polymer, either the bistable poly[n]rotaxane $\mathbf{1} \cdot 4 \mathrm{nPF}_{6}$ or the polymer dumbbell 7 as the control, on 5 micron-wide bottom electrodes followed by electron beam deposition of 5 micronwide metallic top electrodes through a shadow mask. Bottom electrodes were gold or $n$-type polysilicon. The bistable polyrotaxane and polymer dumbbell were diluted in solvent-MeCN and $\mathrm{CH}_{2} \mathrm{Cl}_{2}$, respectively - then spun at $4000 \mathrm{rpm}$ for $45 \mathrm{~s}$. The dilutions were adjusted to yield films of approximately $10 \mathrm{~nm}$, as measured by Dektak profilometry. The films were then baked at $100{ }^{\circ} \mathrm{C}$ for $5 \mathrm{~min}$.

The metallic electrodes were fabricated on a silicon substrate coated with $5000 \AA$ A thermal oxide using photolithography and metal evaporation of $10 \mathrm{~nm}$ titanium and $50 \mathrm{~nm}$ gold, followed by lift-off in $\mathrm{Me}_{2} \mathrm{CO}$. The electrodes were cleaned with an oxygen plasma before deposition of the polymer layer. The silicon electrodes were fabricated from doped $n$-type polysilicon using photolithography, followed by reactive ion etching to transfer the electrode pattern into the $60 \mathrm{~nm}$ thick polysilicon layer. Before use, the electrodes were rinsed with $\mathrm{Me}_{2} \mathrm{CO}$, and the photoresist was stripped in J.T. Baker Aleg-355 at $80{ }^{\circ} \mathrm{C}$ for $30 \mathrm{~min}$. The electrodes were then thoroughly rinsed with $18 \mathrm{M} \Omega$ water and baked at $150{ }^{\circ} \mathrm{C}$ for $5 \mathrm{~min}$. The top electrodes were either $10 \mathrm{~nm}$ titanium and $40 \mathrm{~nm}$ gold (for devices with gold bottom electrodes) or $10 \mathrm{~nm} \mathrm{Ti}$ and $200 \mathrm{~nm} \mathrm{Al} \mathrm{(for} \mathrm{poly-Si}$ bottom electrodes). The electrical characteristics of the devices were evaluated using a Keithley 236 SMU, controlled by LabView software for current-voltage $(I-V)$ and remnant characteristics.

\section{Acknowledgements}

This work was supported under the Semiconductor Research Corporation (SRC) through its focus centers on Functional
Engineered NanoArchitectonics (FENA) and Materials, Structures, and Devices (MSD), the MolApps Program funded by the Defence Advanced Research Projects Agency (DARPA), and The Aerospace Corporation's Independent Research and Development Program. The authors gratefully acknowledge Brendan Foran of The Aerospace Corporation for the transmission electron microscopy.

\section{References}

1 J. R. Heath, Annu. Rev. Mater. Res., 2009, 39, 1-23.

2 S. J. van der Molen and P. Liljeroth, J. Phys.: Condens. Matter, 2010, 22, $1-30$.

3 (a) D. M. Eigler, C. P. Lutz and W. E. Rudge, Nature, 1991, 352, 600603; (b) Z. J. Donhauser, B. A. Mantooth, K. F. Kelly, L. A. Bumm, J. D. Monnell, J. J. Stapleton, D. W. Price Jr., A. M. Rawlett, D. L. Allara, J. M. Tour and P. S. Weiss, Science, 2001, 292, 23032307; (c) F. Moresco, G. Meyer, K.-H. Rieder, H. Tang, A. Gourdon and C. Joachim, Phys. Rev. Lett., 2001, 86, 672-675; (d) A. S. Blum, J. G. Kushmerick, D. P. Long, C. H. Patterson, J. C. Yang, J. C. Henderson, Y. Yao, J. M. Tour, R. Shashidhar and B. R. Ratna, Nat. Mater., 2005, 4, 167-172.

4 (a) N. J. Tao, Phys. Rev. Lett., 1996, 76, 4066-4069; (b) W. Haiss, H. van Zalinge, S. J. Higgins, D. Bethell, H. Hobenreich, D. J. Schiffrin and R. J. Nichols, J. Am. Chem. Soc., 2003, 125, 15294-15295; (c) E. A. Osorio, K. O'Neill, M. Wegewijs, N. StuhrHansen, J. Paaske, T. Bjørnholm and H. S. J. van der Zant, Nano Lett., 2007, 7, 3336-3342; (d) V. Meded, A. Bagrets, A. Arnold and F. Evers, Small, 2009, 5, 2218-2223.

5 (a) M. Alemani, M. V. Peters, S. Hecht, K.-H. Rieder, F. Moresco and L. Grill, J. Am. Chem. Soc., 2006, 128, 14446-14447; (b) B. Y. Choi, S. J. Kahng, S. Kim, H. Kim, H. W. Kim, Y. J. Song, J. Ihm and Y. Kuk, Phys. Rev. Lett., 2006, 96, 156106-156109.

6 P. Liljeroth, J. Repp and G. Meyer, Science, 2007, 317, 1203-1206.

7 (a) D. B. Amabilino and J. F. Stoddart, Chem. Rev., 1995, 95, 27252828; (b) G. A. Breault, C. A. Hunter and P. C. Mayers, Tetrahedron, 1999, 55, 5265-5293; (c) T. J. Hubin and D. H. Busch, Coord. Chem. Rev., 2000, 200, 5-52; (d) J. P. Collin, C. Dietrich-Buchecker, P. Gavina, M. C. Jimenez-Molero and J.-P. Sauvage, Acc. Chem. Res., 2001, 34, 477-487; (e) C. A. Schalley, T. Weilandt, J. Bruggemann and F. Vögtle, Top. Curr. Chem., 2004, 248, 141200; $(f)$ M. S. Vickers and P. D. Beer, Chem. Soc. Rev., 2007, 36, 211-225; (g) J. F. Stoddart, Chem. Soc. Rev., 2009, 38, 1802-1820.

8 (a) Molecular Switches; B. L. Feringa, Ed.; Wiley-VCH: Weinheim, Germany, 2001; (b) D. A. Leigh, J. K. Y. Wong, F. Dehez and F. Zerbetto, Nature, 2003, 424, 174-179; (c) J. V. Hernández, E. R. Kay and D. A. Leigh, Science, 2004, 306, 1532-1537; (d) C. P. Mandl and B. König, Angew. Chem., Int. Ed., 2004, 43, 16221624; (e) A. H. Flood, A. J. Peters, S. A. Vignon, D. W. Steuerman, H.-R. Tseng, S. Kang, J. R. Heath and J. F. Stoddart, Chem.-Eur. $J ., 2004$, 10, 6558-6564; $(f)$ D. W. Steuerman, H.-R. Tseng, A. J. Peters, A. H. Flood, J. O. Jeppesen, K. A. Nielsen, J. F. Stoddart and J. R. Heath, Angew. Chem., Int. Ed., 2004, 43, 6486-6491; (g) H.-R. Tseng, S. A. Vignon, P. C. Celestre, J. Perkins, J. O. Jeppesen, A. Di Fabio, R. Ballardini, M. T. Gandolfi, M. Venturi, V. Balzani and J. F. Stoddart, Chem.Eur. J., 2004, 10, 155-172; (h) Y. Liu, A. H. Flood, P. A. Bonvallet, S. A. Vignon, H.-R. Tseng, T. J. Huang, B. Brough, M. Baller, S. Magonov, S. Solares, W. A. Goddard III, C.-M. Ho and J. F. Stoddart, J. Am. Chem. Soc., 2005, 127, 9745-9759; (i) V. Balzani, A. Credi, B. Ferrer, S. Silvi and M. Venturi, Top. Curr. Chem., 2005, 262, 1-27; (j) T. Ikeda, S. Saha, I. Aprahamian, K. C.-F. Leung, A. Williams, W.-Q. Deng, A. H. Flood, W. A. Goddard III and J. F. Stoddart, Chem.-Asian J., 2007, 2, 76-93; (k) Y.-L. Zhao, W. R. Dichtel, A. Trabolsi, S. Saha, I. Aprahamian and J. F. Stoddart, J. Am. Chem. Soc., 2008, 130, 11294-11296; (l) A. Trabolsi, A. C. Fahrenbach, S. K. Dey, A. I. Share, D. C. Friedman, S. Basu, T. B. Gasa, N. M. Khashab, S. Saha, I. Aprahamian, H. A. Khatib, A. H. Flood and J. F. Stoddart, Chem. Commun., 2010, 46, 871-873.

9 (a) C. P. Collier, G. Mattersteig, E. W. Wong, Y. Luo, K. Beverly, J. Sampaio, F. M. Raymo, J. F. Stoddart and J. R. Heath, Science, 2000, 289, 1172-1175; (b) C. P. Collier, J. O. Jeppesen, Y. Luo, 
J. Perkins, E. W. Wong, J. R. Heath and J. F. Stoddart, J. Am. Chem. Soc., 2001, 123, 12632-12641; (c) M. R. Diehl, D. W. Steuerman, H.R. Tseng, S. A. Vignon, A. Star, P. C. Celestre, J. F. Stoddart and J. R. Heath, ChemPhysChem, 2003, 4, 1335-1339; (d) E. DeIonno, H.-R. Tseng, D. D. Harvey, J. F. Stoddart and J. R. Heath, J. Phys. Chem. B, 2006, 110, 7609-7612.

10 (a) Y. Luo, C. P. Collier, J. O. Jeppesen, K. A. Nielsen, E. DeIonno, G. Ho, J. Perkins, H.-R. Tseng, T. Yamamoto, J. F. Stoddart and J. R. Heath, ChemPhysChem, 2002, 3, 519-525; (b) J. E. Green, J. W. Choi, A. Boukai, Y. Bunimovich, E. Johnston-Halprin, E. DeIonno, Y. Luo, B. A. Sheriff, K. Xu, Y. S. Shin, H.-R. Tseng, J. F. Stoddart and J. R. Heath, Nature, 2007, 445, 414-417.

11 (a) T. J. Huang, H.-R. Tseng, L. Sha, W. X. Lu, B. Brough, A. H. Flood, B. D. Yu, P. C. Celestre, J. P. Chang, J. F. Stoddart and C.-M. Ho, Nano Lett., 2004, 4, 2065-2071; (b) H.-R. Tseng, D. M. Wu, N. X. L. Fang, X. Zhang and J. F. Stoddart, ChemPhysChem, 2004, 5, 111-116.

12 M. A. Olson, A. B. Braunschweig, L. Fang, T. Ikeda, R. Klajn, A. Trabolsi, P. J. Wesson, D. Benitez, C. A. Mirkin, B. A. Grzybowski and J. F. Stoddart, Angew. Chem., Int. Ed., 2009, 48, 1792-1797.

13 (a) R. Klajn, L. Fang, A. Coskun, M. A. Olson, P. J. Wesson, J. F. Stoddart and B. A. Grzybowski, J. Am. Chem. Soc., 2009, 131, 4233-4235; (b) R. Klajn, J. F. Stoddart and B. A. Grzybowski, Chem. Soc. Rev., 2010, 39, 2203-2237; (c) A. Coskun, R. Klajn, L. Fang, M. A. Olson, P. J. Wesson, A. Trabolsi, S. K. Dey, B. A. Grzybowski and J. F. Stoddart, J. Am. Chem. Soc., 2010, 132, 4310-4320.

14 (a) T. Nguyen, H.-R. Tseng, P. C. Celestre, A. H. Flood, Y. Liu, J. I. Zink and J. F. Stoddart, Proc. Natl. Acad. Sci. U. S. A., 2005, 102, 10029-10034; (b) S. Saha, K. C.-F. Leung, T. D. Nguyen, J. F. Stoddart and J. I. Zink, Adv. Funct. Mater., 2007, 14, 685-693; (c) S. Angelos, N. M. Khashab, Y.-W. Yang, A. Trabolsi, H. A. Khatib, J. F. Stoddart and J. I. Zink, J. Am. Chem. Soc., 2009, 131, 12912-12914; (d) K. K. Cotí, M. E. Belowich, M. Liong, M. W. Ambrogio, Y. A. Lau, H. A. Khatib, J. I. Zink, N. M. Khashab and J. F. Stoddart, Nanoscale, 2009, 1, 16-39.

15 J. W. Choi, A. H. Flood, D. W. Steuerman, S. Nygaard, A. B. Braunschweig, N. N. P. Moonen, B. W. Laursen, Y. Luo, E. DeIonno, A. J. Peters, J. O. Jeppesen, K. Xu, J. F. Stoddart and J. R. Heath, Chem.-Eur. J., 2006, 12, 261-279.

16 T. Ye, A. S. Kumar, S. Saha, T. Takami, T. J. Huang, J. F. Stoddart and P. S. Weiss, ACS Nano, 2010, 4, 3697-3701.

17 L. Fang, M. A. Olson, D. Benítez, E. Tkatchouk, W. A. Goddard III and J. F. Stoddart, Chem. Soc. Rev., 2010, 39, 17-29.

18 (a) C. Hamers, F. M. Raymo and J. F. Stoddart, Eur. J. Org. Chem., 1998, 2109-2117; (b) D. L. Simone and T. M. Swager, J. Am. Chem. Soc., 2000, 122, 9300-9301; (c) Y. Okumura and K. Ito, Adv. Mater., 2001, 13, 485-487.

19 (a) J.-L. Weidmann, J.-M. Kern, J.-P. Sauvage, Y. Geerts, D. Muscat and K. Müllen, Chem. Commun., 1996, 1243-1244; (b) S. Menzer, A. J. P. White, D. J. Williams, M. Běhloradský, C. Hamers, F. M. Raymo, A. N. Shipway and J. F. Stoddart, Macromolecules, 1998, 31, 295-307; (c) D. Muscat, W. Köhler, H. J. Räder, K. Martin, S. Mullins, B. Müller, K. Müllen and Y. Geerts, Macromolecules, 1999, 32, 1737-1745; (d) J.-L. Weidmann, J.M. Kern, J.-P. Sauvage, D. Muscat, S. Mullins, W. Köhler, C. Rosenauer, H. J. Räder, K. Martin and Y. Geerts, Chem.-Eur. $J ., 1999,5,1841-1851$; (e) N. Watanabe, Y. Ikari, N. Kihara and T. Takata, Macromolecules, 2004, 37, 6663-6666.

20 (a) B. Odell, M. V. Reddington, A. M. Z. Slawin, N. Spencer, J. F. Stoddart and D. J. Williams, Angew. Chem., Int. Ed. Engl., 1988, 27, 1547-1550; (b) M. Asakawa, W. Dehaen, G. L'abbé, S. Menzer, J. Nouwen, F. M. Raymo, J. F. Stoddart and D. J. Williams, J. Org. Chem., 1996, 61, 9591-9595; (c) G. Doddi, G. Ercolani, P. Mencarelli and A. Piermattei, J. Org. Chem., 2005, 70, 3761-3764; (d) C.-H. Sue, S. Basu, A. C. Fahrenbach, A. K. Shveyd, S. K. Dey, Y. Y. Botros and J. F. Stoddart, Chem. Sci., 2010, 1, 119-125.

21 W. R. Dichtel, O. S. Miljanić, W. Zhang, J. M. Spruell, K. Patel, I. Aprahamian, J. R. Heath and J. F. Stoddart, Acc. Chem. Res., 2008, 41, 1750-1761.
22 (a) W. R. Dichtel, O. S. Miljanić, J. M. Spruell, J. R. Heath and J. F. Stoddart, J. Am. Chem. Soc., 2006, 128, 10388-10390; (b) O. S. Miljanić, W. R. Dichtel, S. Mortezaei and J. F. Stoddart, Org. Lett., 2006, 8, 4835-4838; (c) J. D. Crowley, S. M. Goldup, N. D. Gowans, D. A. Leigh, V. E. Ronaldson and A. M. Z. Slawin, J. Am. Chem. Soc., 2010, 132, 6243-6248.

23 (a) O. S. Miljanić and J. F. Stoddart, Proc. Natl. Acad. Sci. U. S. A., 2007, 104, 12966-12970; (b) M. A. Olson, A. Coskun, L. Fang, A. N. Basuray and J. F. Stoddart, Angew. Chem., Int. Ed., 2010, 49, 3151-3156.

24 W. Zhang, W. R. Dichtel, A. Z. Steig, D. Benítez, J. K. Gimzewski, J. R. Heath and J. F. Stoddart, Proc. Natl. Acad. Sci. U. S. A., 2008, 105, 6514-6519.

25 S. R. Forrest, Nature, 2004, 428, 911-918.

26 C. N. Hoth, P. Schilinsky, S. A. Choulis and C. J. Brabec, Nano Lett., 2008, 8, 2806-2813.

27 P.-L. Anelli, P. R. Ashton, R. Ballardini, V. Balzani, M. Delgado, M. T. Gandolfi, T. T. Goodnow, A. E. Kaifer, D. Philp, M. Pietraszkiewicz, L. Prodi, M. V. Reddington, A. M. Z. Slawin, N. Spencer, J. F. Stoddart, C. Vicent and D. J. Williams, J. Am. Chem. Soc., 1992, 114, 193-218.

28 M. Asakawa, P. R. Ashton, V. Balzani, A. Credi, C. Hamers, G. Mattersteig, M. Montalti, A. N. Shipway, N. Spencer, J. F. Stoddart, M. S. Tolley, M. Venturi, A. J. P. White and D. J. Williams, Angew. Chem., Int. Ed., 1998, 37, 333-337.

29 M. Venturi, S. Dumas, V. Balzani, J. G. Cao and J. F. Stoddart, New J. Chem., 2004, 28, 1032-1037.

30 (a) C. W. Tornoe, C. Christensen and M. Meldal, J. Org. Chem., 2002, 67, 3057-3064; (b) V. V. Rostovtsev, L. G. Green, V. V. Fokin and K. B. Sharpless, Angew. Chem., Int. Ed., 2002, 41, 2596-2599.

31 G. G. Odian, in Principles of Polymerization, Wiley, New York, 1999, 41-90.

32 J. O. Jeppesen, K. A. Nielsen, J. Perkins, S. A. Vignon, A. Di Fabio, R. Ballardini, M. T. Gandolfi, M. Venturi, V. Balzani, J. Becher and J. F. Stoddart, Chem.-Eur. J., 2003, 9, 2982-3007.

33 For an example on the mechanistic investigation on threading polymers through a macrocyclic ring, see: A. B. Deutman, C. Monnereau, J. A. A. W. Elemans, G. Ercolani, R. J. M. Nolte and A. E. Rowan, Science, 2008, 322, 1668-1671.

34 (a) V. Balzani, A. Credi, G. M. Mattersteig, O. A. Matthews, F. M. Raymo, J. F. Stoddart, M. Venturi, A. J. P. White and D. J. Williams, J. Org. Chem., 2000, 65, 1924-1936; (b) T. Ikeda, S. Saha, I. Aprahamian, K. C.-F. Leung, A. Williams, W.-Q. Deng, A. H. Flood, W. A. Goddard III and J. F. Stoddart, Chem.-Asian $J ., 2007,2,76-93$.

35 (a) M. Asakawa, M. Higuchi, G. Mattersteig, T. Nakamura, A. R. Pease, F. M. Raymo, T. Shimizu and J. F. Stoddart, $A d v$. Mater., 2000, 12, 1099-1102; (b) M. R. Bryce, G. Cooke, F. M. A. Duclairoir, P. John, D. F. Perepichka, N. Polwart, V. M. Rotello, J. F. Stoddart and H.-R. Tseng, J. Mater. Chem., 2003, 13, 2111-2117; (c) B. C. Bunker, D. L. Huber, J. G. Kushmerick, T. Dunbar, M. Kelly, C. Marzke, J. Cao, J. O. Jeppesen, J. Perkins, A. H. Flood and J. F. Stoddart, Langmuir, 2007, 23, 31-34.

36 E. W. Wong, C. P. Collier, M. Běhloradský, F. M. Raymo, J. F. Stoddart and J. R. Heath, J. Am. Chem. Soc., 2000, 122, 5831-5840.

37 The remnant measurement is made by sweeping a "write" voltage from zero to positive bias, to negative bias, then back to zero. Between each write voltage step, a "read" measurement is made at a low (non-perturbing) bias. The write voltage is then plotted against the read current.

38 The write voltage for this device was swept from zero to $+2.3 \mathrm{~V}$ to -2 $\mathrm{V}$, then back to zero in $100 \mathrm{mV}$ steps. The device was read at $+0.25 \mathrm{~V}$, well below the threshold for turning the device on.

39 H. Deng, M. A. Olson, J. F. Stoddart and O. M. Yaghi, Nat. Chem., 2010, 2, 439-443.

40 D. R. Stewart, D. A. A. Ohlberg, P. Beck, Y. Chen, R. S. Williams, J. O. Jeppesen, K. A. Nielsen and J. F. Stoddart, Nano Lett., 2004, 4, 133-136.

41 H. B. Yu, Y. Luo, K. Beverly, J. F. Stoddart, H.-R. Tseng and J. R. Heath, Angew. Chem., Int. Ed., 2003, 42, 5706-5711. 